\title{
Cytomorphological Studies on a Saccharum spontaneum L. Clone from the Car-Nicobar Island, India
}

\author{
Narayana Vijayan Nair* and Muthumani Praneetha \\ Cytogenetics Laboratory, Sugarcane Breeding Institute, Coimbatore-641 007, India
}

Received March 14, 2005; accepted March 25, 2005

\begin{abstract}
Summary The Andaman-Nicobar group of Islands is located in the Bay of Bengal between the Indian subcontinental and the Thailand-Malaysia-Indonesia region. A Saccharum spontaneum L. clone was collected from the Car-Nicobar Island during a germplasm-exploration conducted in the Island in March 2003. This is the first collection of S. spontaneum from the Island. The chromosome number of this clone was examined in relation to the distribution of different cytotypes of $S$. spontaneum in the region. The somatic chromosome number of the clone was found to be $2 n=88$, which is not a common cytotype in the neighbouring areas including the Indian subcontinent and the Indonesian archipelago. The possibility of its origin through the natural hybridisation between $2 n=80$ and 96 forms of $S$. spontaneum is discussed. Cytotypes with $2 n=80,96$ and 88 chromosomes are present in Thailand and it is likely that this clone originated in Thailand and spread to Car-Nicobar subsequently.
\end{abstract}

Key words Saccharum spontaneum, Car-Nicobar, Chromosome number.

Saccharum spontaneum L., a wild relative of sugarcane, originated in India (Mukherjee 1957, Roach and Daniels 1987) and has extensive presence in the country. The species shows wide variation in morphology (less than 1 to $8 \mathrm{~m}$ in height) and cytotypes $(2 n=40-128)$. Over 20 cytotypes of $S$. spontaneum have been reported from India with chromosome numbers ranging from $2 n=40$ to 110 (Sreenivasan et al. 2001). All the modern sugarcane varieties are complex interspecific hybrids involving $S$. spontaneum. In view of its importance in sugarcane breeding as a source for high productivity and adaptability, efforts were made to collect, conserve and characterise $S$. spontaneum germplasm since 1933. Several explorations were conducted throughout the country to collect $S$. spontaneum (Naidu and Sreenivasan 1987, Nair et al. 1991, 1993, 2003). An exploration was conducted during March 2003, in the Andaman-Nicobar group of islands located approximately $1200 \mathrm{~km}$ from the Mainland India in the Bay of Bengal, under the National Agricultural Technology Project on Plant Biodiversity, for the collection of Saccharum germplasm. Though some of the important islands were surveyed during this exploration, $S$. spontaneum could be located only in the Car-Nicobar Island. The presence of $S$. spontaneum in Car-Nicobar had been reported earlier by Kurz (1876) and the Botanical Survey of India, Port Blair (herbarium record) in 1976. However its present distribution in the island is very sparse and confined to one particular area in the IAF camp, near Kakana. This clone (IND03-1256) was collected and brought to Coimbatore, for conservation, characterisation and subsequent utilisation.

\section{Materials and methods}

The plant IND03-1256 was grown in large cement pots. Morphological characterisation of the clone was carried out as per Sreenivasan et al. (2001), at 12 months after planting. Mitotic studies

\footnotetext{
* Corresponding author, e-mail: vijay52in@yahoo.com
} 
were carried out using root tip squashes as per Sreenivasan (1969). Chromosome number of the clone was determined after examining 20 cells with well spread chromosomes. Karyotype analysis was carried out as per Sreenivasan (1969) and classified for symmetry as per Stebbins (1958).

\section{Results and discussion}

The plant had slender $(0.71 \mathrm{~cm}$ thick $)$ and medium tall $(165 \mathrm{~cm})$ stalks with moderate tillering. Leaves were narrow (1.01 cm wide) and droopy. Mean internode length was $12.5 \mathrm{~cm}$. The stalks developed pink pigmentation on exposure to sunlight. In gross morphology, it resembled the medium tall forms found elsewhere. The clone did not flower at Coimbatore even after 2 seasons. This is unusual since most of the $S$. spontaneum collections do flower under Coimbatore conditions, irrespective of their geographic origin.

The chromosome number of the clone was found to be $2 n=88$ (Fig. 1). This cytotype is not common in the major areas of distribution including the Indian subcontinent and the Indonesia-New Guinea region. The most common cytotype in India is $2 n=64$, present in both tropical and sub tropical regions of the country. Cytotype with $2 n=88$ is of rare occurrence, with few reports from Sikkim-India (Sreenivasan et al. 2001), Taiwan (Loh 1969) and Thailand (Price 1959). There are over 30 cytotypes of $S$. spontaneum in the range of $2 n=40$ to 128 , representing a polyploid series on the basic numbers of $x=8,10$ and 12 (Sreenivasan et al. 1987). The likely origin of $2 n=88$ types can be through hybridisation between $2 n=80$ and 96 types or between 64 and 112 types. Loh (1969), observed that the $2 n=88$ forms of Taiwan have a hybrid origin involving $2 n=96$ and 80 forms. A similar origin for the $2 n=88$ forms of $S$. spontaneum from Thailand had been suggested by Price (1959) also. The probable origin of the cytotypes with $2 n=88$ was demonstrated by Sreenivasan (1969) by crossing $2 n=64$ and 112 types. All the progenies from this cross had the somatic chromosome number of $2 n=88$.

The Karyotype details pertaining to the clone is presented in Table 1 . The individual chromosome length ranged from 1.20 to $2.00 \mu \mathrm{m}$ with an average length of $1.59 \mu \mathrm{m}$. The difference between largest and smallest chromosome was less than 2. This is well within the range reported for S. spontaneum from the Indian subcontinent (Nair 1968, Sreenivasan 1969). The total chromosome length of the haploid complement was $69.9 \mu \mathrm{m}$. The karyotype was largely symmetrical and falls under the '1a' category of Stebbins (1958). There were 5 'M' chromosomes, 35 ' $\mathrm{m}$ ' chromosomes

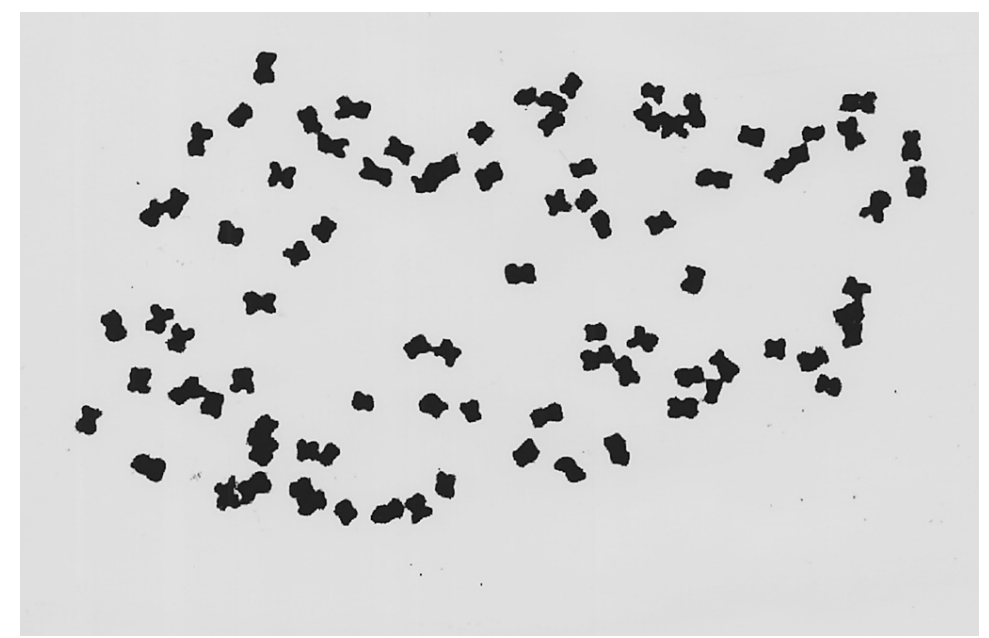

Fig. 1. Somatic metaphase of the Saccharum spontaneum clone IND03-1256 showing $2 n=88$ chromosomes. 
Table 1. Karyotype details of the S. spontaneum clone IND 03-1256

\begin{tabular}{cccccc}
\hline \hline $\begin{array}{c}\text { Length of the } \\
\text { longest } \\
\begin{array}{c}\text { chromosome } \\
(\mu \mathrm{m})\end{array}\end{array}$ & $\begin{array}{c}\text { Length of the } \\
\text { shortest } \\
\text { chromosome } \\
(\mu \mathrm{m})\end{array}$ & $\begin{array}{c}\text { Longest/ } \\
\text { shortest } \\
\text { chromosome }\end{array}$ & $\begin{array}{c}\text { Total haploid } \\
\text { chromosome } \\
\text { length } \\
(\mu \mathrm{m})\end{array}$ & $\begin{array}{c}\text { Karyotype } \\
\text { formula }\end{array}$ & $\begin{array}{c}\text { Karyotype } \\
\text { symmetry }\end{array}$ \\
\hline 2 & 1.2 & $1.67: 1$ & 69.9 & $5 \mathrm{M}+35 \mathrm{~m}+4 \mathrm{sm}$ & $1 \mathrm{a}$ \\
\hline
\end{tabular}

and 4 'sm' chromosomes. Most chromosomes were metacentric and only few were submetacentric, indicative of minimum changes in the chromosome structure (Stebbins 1950). Such karyotypes have been considered as 'generalized types' by Levitsky (1931) and Stebbins (1950).

The Andaman-Nicobar Islands are geographically positioned between the 2 major biodiversity centres viz., the Indian subcontinent and the Indonesian Archipelago. Though there are strictly endemic plants in the islands, major part of the Andaman-Nicobar flora are either of the Indo-Myanmarese-Thailand order or of the Malaysian-Indonesian order (Balakrishnan and Ellis 1996). The possibility of this $S$. spontaneum clone $(2 n=88)$ originating in Car-Nicobar through natural hybridisation between $2 n=96$ and 80 or between 112 and 64 forms is remote, since the parental forms are non-existent in the island. It is more likely that this clone would have originated in the neighbouring landmasses and spreading to Car-Nicobar at a later stage. Both $2 n=80$ and 96 forms of $S$. spontaneum are present in India, but they grow geographically isolated. $2 n=80$ forms have been reported from Arunachal, Assam, Manipur, Bihar, Kerala and Karnataka, while $2 n=96$ forms are confined to Tamil Nadu only. Since $2 n=80$ and 96 forms do not coexist in the same geographical area in India to permit natural hybridisation, the origin of this cytotype $(2 n=88)$ in India is remote. The greater geographical separation between the mainland India and Car-Nicobar also precludes such a possibility. In Indonesia $2 n=96$ and 112 forms are common, $2 n=80$ forms rare and $2 n=64$ types absent, which again does not support an Indonesian origin of this clone. The predominance of $2 n=80$ and 96 forms in Thailand had been reported by Price (1959). Besides, some of the seedlings obtained from the true seeds of $S$. spontaneum collected from Thailand were also found to have $2 n=88$. Price (1959) explained that $2 n=88$ types could have originated from the natural hybridisation of $2 n=96$ and 80 types, both of which are present in Thailand. Thailand is closer to Car-Nicobar geographically than either Indonesia or the Mainland India and it is more likely that this S. spontaneum clone had originated in the Thailand region and spread to Car Nicobar later.

The present study is the first report on the chromosome number of the S. spontaneum from the Andaman-Nicobar Islands.

\section{Acknowledgements}

This work was carried out under the National Agricultural Technology Project on Plant Biodiversity.

\section{References}

Balakrishnan, N. P. and Ellis, J. L. 1996. Andaman and Nicobar Islands. In: Hajra et al. (eds.). Flora of India Part 1. Botanical Survey Of India, Calcutta. pp. 523-538.

Kurz, S. 1876. A sketch of the vegetation of the Nicobar Islands. J. Sat. Soc. Bengal. 45: 105-164.

Levitsky, G. A. 1931. The karyotype in systematics. Bull. Appl. Bot. Genet. Plant Breeding 27: 220-240.

Loh, C. S. 1969. Remarks on S. spontaneum in Taiwan. ISSCT Sugarcane Breeders' Newsletter 123: 4-17.

Mukherjee, S. K. 1957. Origin and distribution of Saccharum. Bot. Gaz. 119: 55-61.

Naidu, K. M. and Sreenivasan, T. V. 1987. Conservation of sugarcane germplasm. In: Proc. Copersucar International Sugarcane Breeding Workshop. Copersucar Technology Centre, Piracicaba-SP, Brazil. pp. 33-53. 
Nair, M. K. 1968. Cytotaxonomical studies in the genus Saccharum and related genera. Cytogenetics of S. officinarum L., S. spontaneum L. and $S$. officinarum $\times S$. spontaneum hybrids. Ph.D. dissertation submitted to the University of Madras, Chennai.

Nair, N. V., Jebadhas, A. W., Sreenivasan, T. V. and Sharma, B. D. 1991. Sugarcane germplasm collection in Manipur and Meghalaya. Indian J. Pl. Genet. Resources 4: 34-39.

- - - and - 1993. Saccharum germplasm collection in Arunachal Pradesh. Indian J. Pl. Genet. Resources 6: 21-26.

— and Somarajan, K. G. 2003. Diversity of Saccharum germplasm in Kerala, India. Plant Genet. Resour. Newsl. 135: $40-43$.

Price, S. 1959. Cytological Studies in Saccharum and allied genera. V. Chromosome numbers in Saccharum, Erianthus, Narenga and Sclerostachya from Thailand and Vietnam. Cytologia 24: 342-347.

Roach, B. T. and Daniels, J. 1987. A review of the origin and improvement of Sugarcane. Proc. Copersucar International Sugarcane Breeding Workshop. Copersucar Technology Centre, Piracicaba-SP, Brazil. pp. 1-32.

Sreenivasan, T. V. 1969. Cytogenetic studies in Saccharum and allied genera. Ph.D. dissertation submitted to the University of Madras, Chennai.

—, Ahloowalia, B. S. and Heinz, D. J. 1987. In: Heinz, D. J. (ed.). Sugarcane Improvement through Breeding. Elsevier, Amsterdam. pp. 211-253.

—, Amalraj, V. A. and Jebadhas, A. W. 2001. Catalogue on Sugarcane Genetic Resources V. Saccharum spontaneum L. Vol. 2. Sugarcane Breeding Institute, (ICAR) Coimbatore, India.

Stebbins, G. L. 1950. Variation and Evolution in Plants. Columbia Univ. Press, New York.

- 1958. Longevity, habitat and release of genetic variability in higher plants. Cold Spring Harb. Symp. Quant. Biol. 23: 365-378. 